Acta vet. scand. $1986,27,80-90$.

From the Department of Food and Environmental Hygiene, and Anatomy and Embryology, College of Veterinary Medicine, Helsinki, Finland.

\title{
EXPERIMENTAL CRYPTOSPORIDIOSIS IN MICE, GALVES AND CHICKEN
}

\author{
By \\ Suvi Pohjola and Lars-Axel Lindberg
}

\begin{abstract}
POHJOLA, SUVI and LARS-AXEL LINDBERG: Experimental cryptosporidiosis in mice, calves and chicken. Acta vet. scand. 1986, 27, 80-90. - Experimental infections attributed solely to Cryptosporidium were carried out in newborn SPF mice, calves and chicken in order to study the prepatency, patency and incubation periods, describe the clinical symptoms and find and describe any correlations between the association of Cryptosporidium with the intestinal mucosa and presence of pathological lesions. The paper also gives the clinical and paarsitological parameters of Cryptosporidium infection of calves from a field survey and compares them to the results of experimental study.
\end{abstract}

parasitological parameters; histopathological lesions.

The minute coccidian protozoan Cryptosporidium, once considered rare and of doubtful clinical significance, is a world-wide newcomer among enteropathogens both in human and veterinary parasitology (reviewed by Tzipori 1983, Anon. 1984). In veterinary medicine Cryptosporidium has been found most frequently in the alimentary tract of young calves (Pohlenz et al. 1978, Tzipori 1983, Stein et al. 1983, Henriksen \& Krogh 1985).

The life cycle of the monoxenous Cryptosporidium is rapid and occurs in the brush border of enterocytes (Tzipori 1983). Since the infection has an impact on the gastrointestinal tract it may lead to maldigestion, malabsorption and malnutrition; abnormal fecal fat, D-xylose test, and low serum coratene levels have been described in human patients (Stemmerman 1980, Tzipori 1980, Sloper 1982), although the earlier reports at first failed to document malabsorption in connection with Cryptosporidium infection (Nime 1976, Meisel 1976). In young calves 
Cryptosporidium infection has been associated with the cachexia syndrome (Hage-Noordam et al. 1982), and the emaciation syndrome (Krogh \& Henriksen 1985), reflecting the chronic implications of the acute disease.

A 5-month survey among neonatal calves carried out in Finland in 1982, revealed oocysts in 36 out of $68(53 \%)$ calves under the age of 20 days (Pohjola et al. 1986). Since differences between herds in animal husbandry methods and management, the occurrence of other enteropathogens in mixed infections, and the original level of exposure to Cryptosporidium oocysts have certainly influenced the clinical and parasitological parameters, we carried out experimental infections attributed solely to Cryptosporidium in mice, calves and chickens, in order 1) to study the prepatency, patency and incubation periods, 2) to describe the clinical symptoms, 3) to transmit the infection between calves and mice, and calves and chickens, 4) to find and describe any correlations between the association of Cryptosporidium with the intestinal mucosa and the presence of pathological lesions. The present paper also gives the clinical and parasitological parameters of the previous field survey and compares them to the results of the experimental study.

\section{MATERIALS AND METHODS}

\section{A nimals}

M i c e: $120,1-4$ days old offspring of Han-NMRI specificpathogen-free (SPF) mice (Orion Diagnostica, Espoo, Finland) were used. The litters were kept in plastic cages with their dams, 1 litter per cage. The dams were provided with pelleted food and water ad lib.

C a lve s: 6 colostrum fed, 2-7 days old Ayrshire calves were purchased from different frams for the experimental study. They were penned individually and fed nonmedicated commercial milk substitute. 5 calves were inoculated with Cryptosporidium oocysts and 1 served as an uninfected negative control. After the sampling was ceased the calves were penned for an additional week before slaughtering was performed to obtain tissue samples.

The 68 calves of the field survey originated from 8 housed herds, which were selected on the ground of a previous history of diarrhea (Pohjola et al. 1986). 
C h i ck e n s: 30 one-day-old broiler chickens of Pilch (Saarioinen Oy, Sahalahti, Finland) were housed in flocks of 10 birds and fed commercial food and water ad lib.

\section{Source and preparation of inocula, inoculation}

Two types of inocula were used in the cross-transmission experiments.

I n o c u lum I, fecal material obtained from a 9-day-old calf, naturally infected with Cryptosporidium, was kindly provided by Dr. Sv. Aa. Henriksen (State Veterinary Serum Laboratory, Copenhagen, Denmark). The inoculum was purified by treatment in ethanol (final concentration of $60 \%$ ) for $2 \mathrm{~h}$ and washed twice in $0.9 \%$ saline by centrifugation at $500 \mathrm{~g}$ for $10 \mathrm{~min}$. The absence of bacterial contamination was checked by culturing the seriment on $5 \%$ bovine blood agar and the morphology of the oocysts was examined from the smeared sediment stained with the modified Ziehl-Neelsen technique (Henriksen \& Pohlenz 1981). $0.05 \mathrm{ml}$ of the fecal sediment $(20 \% \mathrm{v} / \mathrm{v}$ in $0.9 \% \mathrm{NaCl}$ ) was administered intraesophageally with a stomach tube of 25 gauge to $1001-4$ day old mice, each weighing about 2 g. 20 mice served as uninfected controls. The final oocyst count of inoculum I was not evaluated. One $\mathrm{ml}$ inoculum I was also administered into the crop of 20 one-day-old chickens, 10 chickens served as uninfected controls.

Gut homogenates were collected from the SPF mice, homogenized with a tissue grinder and prepared in the previous manner for in o c u l u m I f for the experimental calves. An oocyst count of about $3 \times 10^{4}$ in $5 \mathrm{ml}$ of the inoculum was mixed with $100 \mathrm{ml}$ of warmed milk and given intraruminally with the stomach tube to 5 calves.

\section{Clinical observations and sampling}

The experimental animals were observed for a period of 2 weeks. Signs of illness, intake of food and the rectal temperatures of the calves were recorded; 4 mice and 2 chickens were necropsied, and fecal specimens were collected from calves at $12 \mathrm{~h}$ intervals beginning at $60 \mathrm{~h}$ post-inoculationem.

Since in previous studies we had found that some oocysts may have poor affinity for the Giemsa stain (Jokipii et al. 1983) or were not acid-fast at all (Pohjola et al. 1986), 3 
experimental calves were sampled at $6 \mathrm{~h}$ intervals between the 74 th and 98 th $h$ post-infectionem.

\section{Histology}

Tissue samples were taken from all infected mice and 3 calves as quickly as possible after decapitation or slaughter of the animals. The mice were sampled from the terminal part of the ileum, the calves from the following areas: initial and terminal jejunum, terminal ileum, caecum and colon. The samples were fixed in neutral $10 \%$ formalin, dehydrated in ethanol and embedded in paraffin. Sections cut at $5 \mu \mathrm{m}$ were stained with hematoxylin-eosin (HE) or Giemsa (mice), or with HE (calves).

The remaining part of the intestine from each mouse was homogenized in saline, as was the terminal part of the large intestine from the chickens.

\section{Detection of Cryptosporidium}

Gut homogenates from mice and chicken and fecal specimens from calves were smeared on microscope slides and stained with the modified Ziehl-Neelsen technique (Henriksen \& Pohlenz 1981). The stained smears were examined under oil-immersion at a magnification of $100 \times$. The grade of murine cryptosporidiosis was scored by comparing the means of oocyst numbers counted for 20 fields on each microscope slide.

\section{RESULTS}

Cryptosporidiosis in mice

Cryptosporidium oocysts were first detected at $84 \mathrm{~h}$. Patterns of oocysts production are presented in Fig. 1. The number of oocysts reached its first culmination point at $132 \mathrm{~h} ; 20-30 \%$ of the oocysts at this point stained moderately, were thin-walled and showed ruptures in the walls. At $144 \mathrm{~h}$ the oocyst number fell to on the level recorded at $108 \mathrm{~h}$. At $180 \mathrm{~h}$ it reached a second culmination point, and almost no ruptured oocysts were detected. After that the production of oocysts gradually ceased; the level at $252 \mathrm{~h}$ was the same as at $84 \mathrm{~h}$, and at $312 \mathrm{~h}$ no more oocysts were detected. No signs of clinical illness were detected during the study period either in the newborn inoculated and control or in adult mice were detected during the study period. 


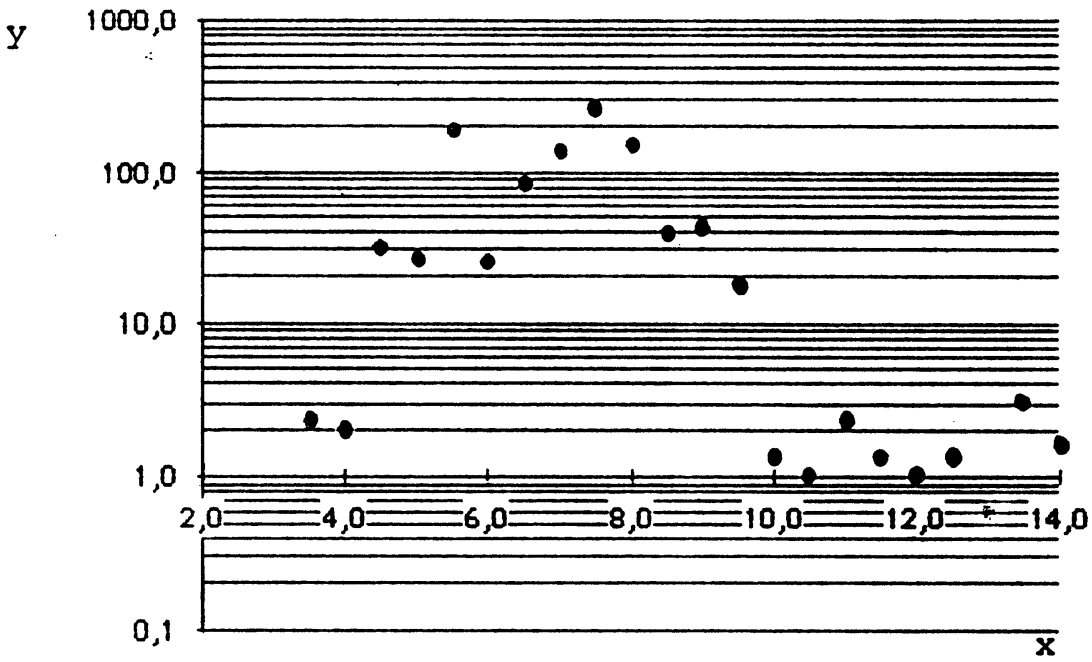

Figure 1. Patterns of oocyst shedding in experimentally infected mice.

(x: days after inoculation

$y$ : means of oocyst numbers of 20 fields $(\times 1000)$.

Oocysts from the experimentally infected mice were morphologically indistinguishable from those from the naturally infected calves: $3-6 \mu \mathrm{m}$, round, red bodies on a green background. There were some vacuoles and dots inside the oocysts. The thickness of the oocyst walls varied.

In Giemsa stained sections from inoculated mice cryptosporidia were seen along the striated border of epithelial cells in the terminal ileum (Fig. 2). Areas with numerous inflammatory cells were also seen in the epithelium and lamina propria of the villi (Fig. 3). There were no marked structural changes in the mucosa compared to that of the control mice.

\section{Cryptosporidiosis in calves}

After a mean incubation period of 3.6 days (range $3-4$ d, S.D. 0.4) the inoculated calves developed signs of illness, characterized by depression, anorexia and profuse yellowish diarrhea, which lasted 6-9 days (mean 7.4 d, S.D. 1.5). The rectal temperatures of all the calves ranged within normal limits $\left(37.9^{\circ} \mathrm{C}-39.1^{\circ} \mathrm{C}\right.$ ) throughout the observation period. Oocysts were first detected after a mean of 4 days (range $3-5 \mathrm{~d}$, S.D. 0.8 ) and shedding continued for 3 to 8.5 days (mean $6.7 \mathrm{~d}$, S.D. 2.2). Shedding of oocysts 

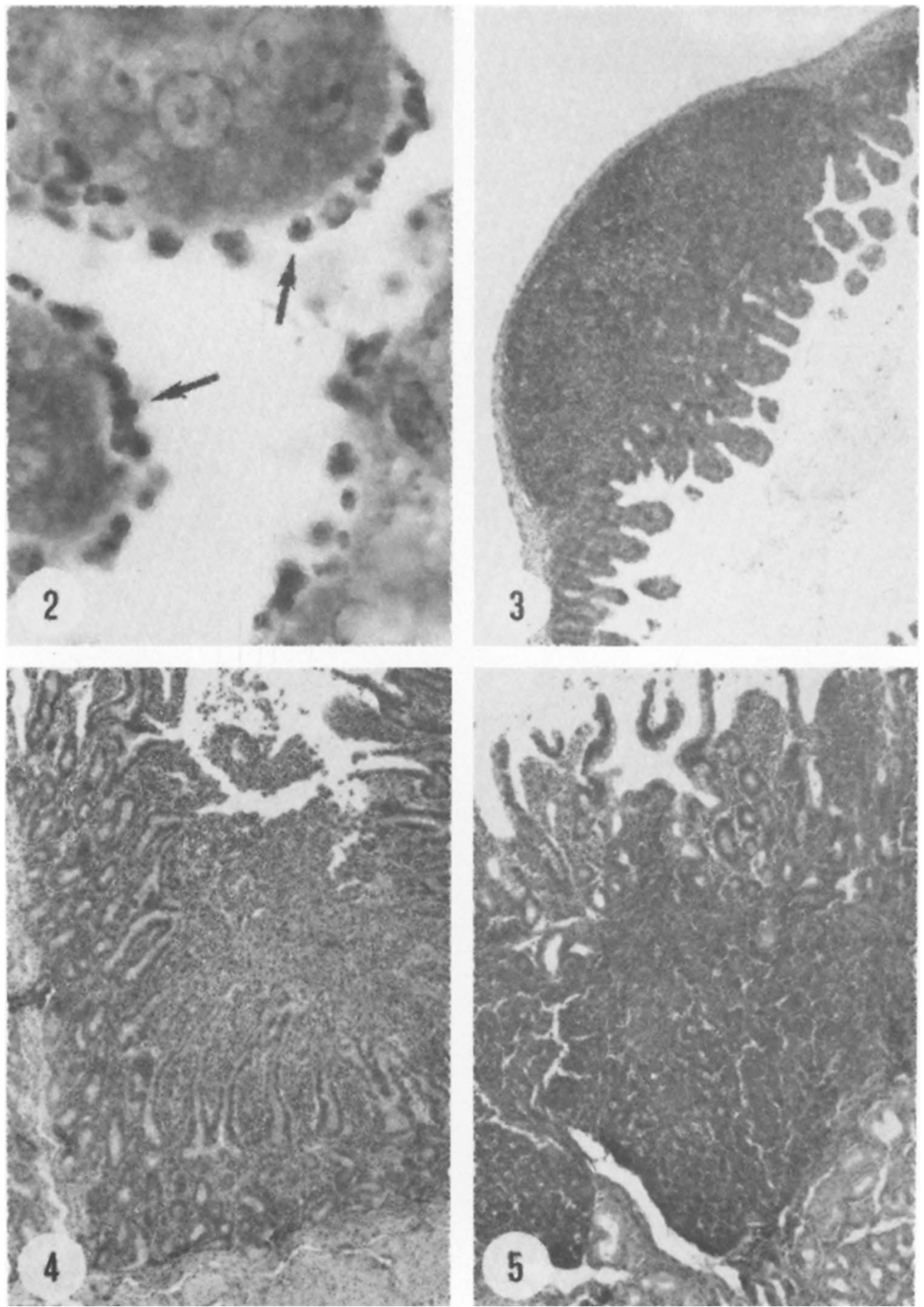

Figu re 2. Cryptosporidia (arrows) along the striated border of epithelial cells in the terminal ileum of an experimentally infected mouse. x 1600 .

Figure 3. An area with numerous inflammatory cells in the lamina propria in the terminal ileum of an experimentally infected mouse. $x 70$.

Figu re 4. Shortened and fused villi in the jejunum of an infected calf. $x 70$

Figure 5. An area with inflammatory cells in the epithelium and lamina propria in the jejunum of an infected calf. $x 70$. 

was intermittent in 4 calves. The mean number of days of subclinical shedding observed in all infected calves was 5 days (range $4-7$ d, S.D. 1-2). The optimal day for the detection of oocysts was postinfection day 7 , when all the infected calves were shedding oocysts. Neither signs of gastrointestinal illness nor shedding of oocysts were detected in the control calf.

In the field survey, 12 out of $36(33 \%)$ Cryptosporidium positive calves were shedding oocysts for the first time at 5 days of age and $10(28 \%)$ at 7 days of age. The shortest obvious prepatent period of 3 days was recorded in $4(11 \%)$ calves and shedding rarely began after 10 days of age $(28 \%)$. The patent period in most calves continued for about 1 week; the optimal day for diagnosis was postinfection day 10 , when 21 out of 36 $(58 \%)$ calves were shedding oocysts. Manifest enteritis was associated with shedding of oocysts in $82 \%(9 / 11)$ of the calves during their first week of life. In 6 of those calves Cryptosporidium was found alone and in 3 calves it was found rotavirus. The diarrheic feces were described as watery and yellowish, sometimes containing flakes of undigested milk. Subclinical shedding of oocysts was detected in $25(69 \%)$ calves.

In the present study, with more frequent sampling, oocysts were first recorded in 2 calves at $86 \mathrm{~h}$ postinfection, but most of them were not acid-fast. Fecal samples taken at 92 and $98 \mathrm{~h}$ postinfection revealed numerous acid-fast oocysts.

In infected calves, mucosal changes were detected mainly in the terminal jejunum and ileum. Almost no changes were seen in the caecum or colon. The villi of affected areas were shorter than in control animals, and often fused together (Fig. 4). The epithelium was low and irregular. Infiltration of inflammatory cells in the epithelium and lamina propria was frequently seen (Fig. 5).

\section{Cryptosporidiosis in chicken}

None of the chickens experienced any signs of clinical illness during the study, and Cryptosporidium oocysts could not be demonstrated from their gut contents.

\section{DISCUSSION}

In the present cross-transmission experiment, Cryptosporidium infection was transmitted by oral inoculation of 
oocysts between calves and mice, but not between calves and chickens. Oocysts demonstratfd from naturally infected calves as compared to oocysts harvested from experimentally infected mice and calves were morphologically indistinguishable, they were equal in shape and size and had similar staining properties, thus strengthening the earlier observation of an organism lacking host-specificity (Tzipori et al. 1980, Current et al. 1983). However, the failure of the transmission attempt between calves and chickens demonstrated that the lack of host-specificity may occur within each vertebrate class, as suggested by Levine in 1984. There has been also suspicion of the occurrence of different strains of Cryptosporidium, e.g. bovine isolates from Scotland have resulted in enteric infections of chickens, whereas Australian isolates have not (Tzipori et al. 1983).

The passage of Cryptosporidium through experimental mice seemed not to alter their pathogenicity for calves, since the original calf isolate resulted only in subclinical infections in mice, whereas heavy shedding of oocysts and clinical symptoms was observed in experimental calves. Our results are in agreement with experimental work carried out with laboratory mice, in whom only subclinical and transient infections were successful (Sherwood et al. 1982). Contrary to ordinary mice, nude mice (nu/nu, BALB/c) affected with cryptosporidia have shown infection characterized by diarrhea and occasional deaths (Heine et al. 1984). The pathogenicity of Cryptosporidium for calves has been demonstrated in experimental monoinfection (Heine et al. 1984) as well, as in natural infections attributed solely to the organism (Tzipori et al. 1980, Anderson \& Bulgin 1981).

Features of the life cycle of Cryptosporidium of mice and calves resembled each other. The shortest prepatent period in both species took an average of 3 to 4 days, after a patency lasting on average between 7 to 10 days, the host was free of infection. Self-limiting infections have been recorded with similar parasitological parameters in both natural and experimental infections in these and other species of animals as well as humans (Sherwood et al. 1982, Current et al. -983, Heine et al. 1984).

Two types of oocysts, thin-walled and thick-walled, as seen in the present study, have also been recorded in vivo in mice as also in vitro using chicken embryos. Rupture of the thin-walled oocysts have been suggested as representing the pattern of endogenous autoinfection (Current \& Reese 1982, Current \& Long 
1983), it also may explain the intermittent shedding of oocysts observed in experimentally infected calves as also in calves from the field.

Asymptomatic shedding of oocysts seemed to be frequent among calves from the field; diarrhea was most frequently associated with Cryptosporidium infection during the first week of life. The significance of asymptomatic shedding of Cryptosporidium oocysts with respect to the zoonotic transmission of infection is still obscure, as the number of oocysts excreted has not yet been evaluated in asymptomatic versus clinical infection and the infectious dose of oocysts for man and animals is not known. So far, diarrheic calves shedding oocysts have been reported to be a source of human cryptosporidiosis (Anderson et al. 1982, Reese et al. 1982, Current et al. 1983, Rahaman et al. 1984, Pohjola et al. in print).

The difference in the optimal day of diagnosis, postinfection day 10 in the field as compared with postinfection day 7 in experimental conditions, suggests smaller and later initial infectious challenge in the field, since in experimental work the prepatency has been delayed by applying contact transmission of infection instead of direct ionculation of oocysts (Tzipori et al. 1983). The symptoms of Cryptosporidium infection in calves resembled earlier descriptions (Sanford et al. 1982, Tzipori et al. 1983), and were not different from other enteric infections. It cannot be ignored that during the first week of life Cryptosporidium alone was a sufficient cause of diarrhea.

The degree of infection, mucosal injury and severity of disease have been reported to correlate with each other (Tzipori 1983) - a phenomen which was also seen in this study. Cryptosporidium in mice resulted only in transient subclinical infections with no marked histopathological changes, whereas in calves the infection may result in asymptomatic or symptomatic enteric infection with more prominent changes in intestinal architecture. In calves the predominant histopathological changes were found in the posterior half of the small intestine, in the caudal jejunum and the ileum, whereas no changes occurred in caecum and colon. The morphological changes, such as villus blunting and fusion, are nonspecific except that endogenous stages of the parasite were found in the tips of the villi, but have been thought to explain the functional lesions and to reduce the absorptive surface (Pohlenz et al. 1984). Low levels of 
microvillar disacchridases (sucrase, lactase and/or maltase) have been reported in infected animals (Tzipori et al. $1982 \mathrm{a}$, Tzipori $1982 \mathrm{~b}$ ), reflected as malabsorption and/or maldigestion and diarrhea (Pohlenz et al. 1984, Heine et al. 1984). Mucosal destruction by parasite metabolites or toxins has also been suggested (Tzipori 1983). The morphological changes observed in the present study might have been more prominent if the calves had been slaughtered while still shedding oocysts. Since there is so far no treatment for Cryptosporidium, every effort should be made to reduce the fecal contamination of premises where newborn and young calves are being reared.

\section{REFERENCES}

Anderson, B. C. \& M. S. Bulgin: Enteritis caused by Cryptosporidium in calves. VM/SAC 1981, 76, 865-868.

Anderson, B. C., T. Donndelinger, R. M. Wilkins \& J. Smith: Cryptosporidiosis in a veterinary student. J. Amer. vet. med. Assoc. 1982, 180, 408—409.

Anon.: Cryptosporidiosis. Lancet. 1984, $i, 492-493$.

Current, W. L. \& N. C. Reese: Symposium. The biology of Cryptosporidium (abstract). Proc. 27th Ann. Mtt. Amer. Assoc. Vet. Parasitol. 1982, p. 24-25.

Current, W. L., N. C. Reese, J. V. Ernst, W. S. Bailey, M. B. Heyman \& W. M. Weinstein: Human cryptosporidiosis in immunocomponent and immunodeficient persons. N. Engl. J. Med. 1983, $308,1252-1257$.

Current, W. L. \& P. L. Long: Development of human and calf Cryptosporidium in chicken embryos. J. infect. Dis. 1983, 148, 11081113.

Hage-Noordam, A. W., J. M. A. \& P. W. de Leeuw: Cryptosporidium in veal calves affected with cachexia. Tijdschr. Diergeneesk. 1982, 107, 497-502.

Heine, J., J. F. L. Pohlenz, H. W. Moon \& G. N. Woode: Enteric lesions in gnotobiotic calves monoinfected with Cryptosporidium species. J. infect. Dis. 1984, 150, 768-775.

Henriksen, S. A.\& J. F. L. Pohlenz: Staining of Cryptosporidia by a modified Ziehl-Neelsen technique. Acta vet. scand. 1981, 22, $594-596$.

Henriksen, Sv. Aa. \& H. V. Krogh: Bovine cryptosporidiosis in Denmark. I. Prevalence, age distribution and seasonal variation. Nord. Vet.-Med. 1985, 37, 34-41.

Jokipii, L., S. Pohjola \& A. M. M. Jokipii: Cryptosporidium, a frequent finding in patients with gastrointestinal symptoms. Lancet 1983, $i i, 358-361$. 
Krogh, H. V. \& Sv. Aa. Henriksen: Bovine cryptosporidiosis in Denmark. 2. Cryptosporidia associated with neonatal calf diarrhea. Nord. Vet.-Med. 1985, 37, 42-47.

Levine, N. C.: Taxonomy and review of coccidian genus Cryptosporidium (Protozoa, Apicomplexa). J. Protozool. 1984, 31, $94-98$.

Meisel, J. L., D. R. Perera, C. Meligro \& C. E. Rubin: Overwhelming watery diarrhea associated with cryptosporidium in an immunosuppressed patient. Gastroenterology 1976, 70, 1156-1160.

Nime, F. A., J. D. Burek, D. L. Page, M. A. Holscher \& J. H. Yardley: Acute enterocolitis in a human being infected with the protozoan Cryptosporidium. Gastroenterology 1976, 70, 592_598.

Pohjola, S. H. Oksanen, E. Neuvonen, P. Veijalainen \& K. Henriksson: Certain enteropathogens in calves of Finnish dairy herds with recurrent outbreaks of diarrhea. Prev. Vet. Med. 1986, 3, 547558.

Pohjola, S., H. Oksanen, L. Jokipii \& A. M. M. Jokipii: Outbreak of cryptosporidiosis among veterinary students. Scand. J. infect. Dis., in print.

Pohlenz, J., H. W. Moon, N. F. Cheville \& W. J. Bembrick: Cryptosporidiosis as a probable factor in neonatal diarrhoea of calves. J. Amer. vet. med. Assoc. 1978, 172, 452-457.

Rahaman, A. S. M. H., S. C. Sanyal, K. A. Al-Mahmud, A. Sobhan, K. S. Hossain \& B. C. Anderson: Cryptosporidiosis in calves and their handlers in Bangladesh. Lancet 1984, $i i, 221$.

Reese, N. C., W. L. Current, J. V. Ernst \& W. S. Bailey: Cryptosporidium of man and calf: a case report and results of experimental infections in mice and rats. Amer. J. trop. med. Hyg. 1982, 31, 226-229.

Sanford, S. E. \& G. K. A. Josephson: Bovine cryptosporidiosis. Clinical and pathological findings in forty-two scouring neonatal calves. Canad. vet. J. 1982, 23, 343-347.

Sherwood, D., K. W. Angus, D. R. Snodgrass \& S. Tzipori: Experimental cryptosporidiosis in laboratory mice. Infect. Immun. 1982, $38,471-475$.

Sloper, K. S., R. R. Dourmashkin, R. B. Bird, G. Slavin \& A. D. B. Webster: Chronic malabsorption due to cryptosporidiosis in a child with immunoglobulin deficiency. Gut 1982, 23, 80-82.

Stein, E., J. Boch, J. Heine \& G. Henkel: Der Verlauf natürlicher Cryptosporidium-Infektionen in vier Rinderzuchtbetrieben. (Course of natural Cryptosporidium infektions on 4 cattle breeding farms). Berl. Münch. tierärztl. Wschr. 1983, 96, 222-225.

Stemmermann, G. N., T. Hyashi, G. A. Glober, N. Oishi \& R. I. Frankel: Cryptosporidiosis, report of a fatal case complicated by disseminated toxoplasmosis. Amer. J. trop. Med. Hyg. 1980, 69, $637-642$.

Tzipori, S.: Cryptosporidiosis in animals and humans. Microbiol. Rev. $1983,47,84-96$. 
Tzipori, S., K. W. Angus, I. Campbell \& E. W. Gray: Experimental infection of lambs with cryptosporidium isolated from human patient with diarrhoea. Gut 1982 a, 23, 71-74.

Tzipori, S., K. W. Angus, E. W. Gray \& I. Campbell: Vomiting and diarrhea associated with Cryptosporidium infection. N. Engl. J. Med. 1980, 303, 818.

Tzipori, S., M. Smith, T. Makin \& C. Halpin: Enterocolitis in piglets caused by Cryptosporidium sp. purified in calf faeces. Vet. Parasitol. 1982 b, 11, 121-126.

\section{SAMMANDRAG}

Experimentell cryptosporidios hos möss, kalvar och kycklingar.

Experimentella infektioner tillskrivna enbart Cryptosporidium genomfördes på nyfödda SPF möss, kalvar och kycklingar för att studera prepatens, patens och inkubationsperioder, beskriva kliniska symptom och finna och beskriva samband mellan förekomst av Cryptosporidium vid tarmväggens mukosa och patologiska förändringar i tarmen. Artikeln ger också de kliniska och parasitologiska parametrarna för Cryptosporidium infektion hos kalvar i en fältstudie, och jämför dem med de experimentella resultaten.

(Received December 4, 1985).

Reprints may be requested from: Suvi Pohjola, the College of Veterinary Medicine, Department of Food and Environmental Hygiene, P. O. Box 6, SF-00551 Helsinki, Finland. 